\title{
A comparison of the effectiveness of sonication, high shear mixing and homogenisation on improving the heat stability of whey protein solutions
}

Li Ling A. Koh ${ }^{\mathrm{a}, \mathrm{b}}$, Jayani Chandrapala ${ }^{\mathrm{b}}$, Bogdan Zisu ${ }^{\mathrm{c}}$, Gregory J. O. Martin ${ }^{\mathrm{a}}$, Sandra E. Kentish ${ }^{\mathrm{a}, *}$, Muthupandian Ashokkumar ${ }^{\mathrm{b}}$

a Department of Chemical and Biomolecular Engineering, The University of Melbourne, VIC 3010, Australia

${ }^{\mathrm{b}}$ School of Chemistry, The University of Melbourne, VIC 3010, Australia

${ }^{\mathrm{c}}$ Dairy Innovation Australia Limited, Werribee, VIC 3030, Australia

* Corresponding Author

Sandra E. Kentish

Department of Chemical and Biomolecular Engineering

The University of Melbourne

VIC 3010

Australia

Tel: $\quad+61383446682$

Fax: $\quad+61383444153$

Email: sandraek@unimelb.edu.au 


\begin{abstract}
Upon ultrasonic treatment at $20 \mathrm{kHz}$, protein aggregates in a dairy whey solution were broken down. In addition, when sonication was applied to a heated solution of denatured and aggregated proteins, there was a dramatic reduction in viscosity and aggregate size, which was maintained after re-heating. This observed heat stability may be due to shear forces that are induced by acoustic cavitation. To determine whether high shear mixing or homogenisation is able to cause similar effects to that of acoustic cavitation, sonication, high shear mixing and homogenisation were performed on $5 \mathrm{wt} \%$ whey protein concentrate solutions at identical energy density levels, which was based on the power drawn in each system. Homogenisation provided similar particle size and viscosity reductions as sonication while high shear mixing was less efficient in decreasing particle size. Cavitation was shown to be absent in both the mixing and homogenisation configurations, indicating that the shear forces generated are responsible for the observed particle size and viscosity reduction. In addition, heat stability was achieved in all systems indicating that a combination of heat treatment and any method that generates high shear forces can be used to improve the heat stability of whey proteins.
\end{abstract}

\title{
Keywords
}

Ultrasonics; high shear mixing; homogenisation; heat stability; whey 


\section{Introduction}

Dairy whey is a by-product of the cheese-making process and is considered an important dairy product due to its significant protein and lactose content. However, a major concern restricting its use is its low heat stability: exposure to temperatures above $70{ }^{\circ} \mathrm{C}$ leads to denaturation and subsequent aggregation of the proteins (Wang et al., 2006). This results in excessive thickening or gelling when the protein solution is further heated in downstream processes (Morr \& Richter, 1999).

The use of pre-heating, or fore-warming, to induce heat stability was first established in the 1940s as a treatment for condensed milk streams (Deysher et al., 1929; Singh, 2004; Webb \& Bell, 1942). The denaturation of the whey proteins is irreversible and hence, once induced in a fore-warming step provides a heat-stable product (Tolkach \& Kulozik, 2007; Wang et al., 2006). However, this approach is ineffective for spray-dried products as the resulting increases in viscosity that occur after heating restrict the ability to generate a feed stream of high solids content. Furthermore, the aggregation that occurs during heating can result in later phase separation and protein precipitation.

More recently, Ashokkumar and co-workers (2009) have developed a combination of heat and ultrasonic treatment that is effective at resolving these issues. Protein aggregates in the dairy whey solution are broken down upon ultrasonic treatment at $20 \mathrm{kHz}$ with increased solution clarity, reduced viscosity, reduced gelation times and increased gel strength (Zisu et al., 2011). The reduction in viscosity of whey solutions is particularly significant as it may allow solutions of higher solids content to be processed effectively in spray driers, evaporators and membrane filtration units. Overall energy requirements may also be reduced. In addition, when sonication is applied to a heated solution of denatured and aggregated proteins, there is a dramatic reduction in viscosity and aggregate size. Ashokkumar and co-workers (2011) speculated that the reduction in particle size and viscosity is due to the disruption of hydrophobic interactions by shear forces that are generated during acoustic cavitation. Acoustic cavitation is a phenomenon in which bubbles present in a liquid medium grow and collapse because of pressure fluctuations caused by ultrasound waves. During bubble collapse, physical and chemical effects are generated. Physical effects include shear, turbulence and micro-streaming while formation of highly reactive radicals is one example of chemical effects (Ashokkumar et al., 2009).

Similar changes in the particle size of whey protein aggregates have been observed in physical shear and high pressure processes (Bouaouina et al., 2006; Dissanayake \& Vasiljevic, 2009; Grácia-Juliá et al., 2008; Onwulata et al., 2002; Paquin, 1999). High shear mixing of small volumes is typically performed in the laboratory using an Ultra-Turrax unit: the liquid medium is drawn axially into the dispersion head at 
high rotation speeds of the rotor and forced radially out the slots of the stator, producing large shear and thrust forces that provide mixing and disrupt cells (Ika, 2009).

In homogenisation or microfluidisation, high pressures are applied over a short period of time. For homogenisation, a fluid under pressure is forced through a small orifice or a valve, resulting in a large pressure gradient between the inlet and the outlet of the valve (Floury et al., 2004; Grácia-Juliá et al., 2008). Intense shear forces, cavitation and heat are produced. The amount of shear and cavitation generated determines the level of aggregate disruption while the extent of denaturation and aggregation is dependent on the amount of heat generated. In a microfluidiser, a liquid is split into two streams, which are then recombined in a reacting chamber at high pressures. Aggregate disruption, in this case, is thought to be mainly due to hydrodynamic cavitation (Paquin, 1999).

The use of combined heat and shear to form a 'microparticulated' whey stream with small protein aggregates, which have a creamy mouth-feel, is well established (Oldrup, 2006; Onwulata et al., 2002). A more limited number of studies have shown improved heat stability upon such a combination of heat and shear treatment. Our own work has clearly shown the combination of heat and sonication to be effective in this regard (Zisu et al., 2010). Dissanayake and Vasiljevic (2009) observed an increase in heat coagulation time of whey protein retentate samples that were microfluidised at $140 \mathrm{MPa}$. They also showed that a combination of heat treatment followed by microfluidisation further increased the heat coagulation time. Somewhat differently, Iordache and Jelen (2003) found that after such a combination of heat and microfluidisation, the whey protein was still somewhat sensitive to secondary heat-induced coagulation. Further, in early studies on condensed milk, the combination of heat with downstream homogenisation was ineffective - the resulting product was less heat stable than when fore-warming alone was used (Deysher et al., 1929; Webb \& Bell, 1942). The effect of shear, induced either by homogenisation or acoustic cavitation, upon a heated dairy stream is thus unclear.

In this study, a $20 \mathrm{kHz}$ ultrasonic horn, an Ultra-Turrax mixing unit and a homogeniser were used to investigate the physical effects of acoustic cavitation, high shear mixing and high pressure on 5 wt $\%$ reconstituted whey protein concentrate (WPC80) solution by monitoring aggregate size and viscosity. The objective of the work was to determine whether physical shear is able to reduce the viscosity of whey protein solutions and induce a heat stability effect similar to that caused by acoustic cavitation. Based on the power drawn in each system, a qualitative comparison of energy efficiency and heat stability has been made using identical energy density in the sonicator, mixer and homogeniser. 


\section{Materials and Methods}

\section{$2.1 \quad$ Materials}

Whey protein concentrate (WPC80) powder containing $81.5 \%$ protein, $10.4 \%$ lactose and $4.4 \%$ fat was provided by Warrnambool Cheese and Butter Factory (Allansford, Victoria, Australia). Ammonium molybdite tetrahydrate (Chem-Supply, $81.0 \%$ ), phenol (Chem-Supply, $99.5 \%$ ), potassium iodide (ChemSupply, $99.0 \%$ ), potassium hydrogen phthalate (Ajax, $99.8 \%$ ) and sodium hydroxide (Chem-Supply, 97.0\%) were used as supplied.

In all experiments, the required amount of WPC80 was reconstituted in deionised water at ambient temperature $\left(22{ }^{\circ} \mathrm{C}\right)$ to give $5 \mathrm{wt} \%$ WPC80 solutions. After powder dissolution, the solution was left to stir for an hour then stored overnight in the refrigerator at $4{ }^{\circ} \mathrm{C}$. Before use, the solution was equilibrated at $25^{\circ} \mathrm{C}$.

A single-phase energy cost meter (Arlec, Victoria, Australia) was used to measure the power drawn from the power supply for the sonicator and the Ultra-Turrax unit. Power drawn for the homogeniser was recorded using an in-built three-phase energy cost meter.

\section{$2.2 \quad$ Methods}

Figure 1 depicts a flow chart of experiments performed. A combination of different heat treatments on the native solution served as controls (Samples 1, 5 and 9). A portion of the native solution was also treated by sonication (Sample 2), mixing (Sample 3) or homogenisation (Sample 4). Pre-heated solutions were also treated by sonication (Sample 6), mixing (Sample 7) and homogenisation (Sample 8). Further heat treatment, or post-heating, was then done to these samples (Samples 10, 11 and 12).

\subsubsection{Sonication}

$60 \mathrm{ml}$ of reconstituted WPC80 solution was sonicated in a glass vessel using a $20 \mathrm{kHz}, 400 \mathrm{~W}$ ultrasonic processor and $19 \mathrm{~mm}$ diameter horn (Branson Ultrasonics, Connecticut, USA) at an amplitude of $50 \%$ for $1 \mathrm{~min} 31 \mathrm{~s}$ to provide an energy density of $153 \mathrm{~J} / \mathrm{ml}$. The power drawn and calorimetric power were $101 \mathrm{~W}$ and $31 \mathrm{~W}$ respectively, indicating an overall energy efficiency of $31 \%$. The energy density was calculated using Equation 1. During sonication, chilled water was circulated through the cooling jacket of the glass vessel to maintain the solution temperature at $5 \pm 1{ }^{\circ} \mathrm{C}$.

$$
\text { energy density }(\mathrm{J} / \mathrm{ml})=\frac{\text { power drawn }(\mathrm{W}) \times \text { time }(\mathrm{s})}{\operatorname{volume}(\mathrm{ml})}
$$




\subsubsection{Ultra-Turrax High Shear Mixing}

$60 \mathrm{ml}$ of reconstituted WPC80 solution was mixed at high shear rates using a T25 Basic Ultra-Turrax unit (Ika-Werke, Staufen, Germany) at speed dial 4, which corresponded to $17500 \mathrm{~min}^{-1}$. The power drawn was $70 \mathrm{~W}$ and the calorimetric power was $9.8 \mathrm{~W}$, indicating an overall energy efficiency of $14 \%$. To ensure an equivalent energy density to sonication $(153 \mathrm{~J} / \mathrm{ml})$, mixing was conducted for 2 min $11 \mathrm{~s}$. Similar to sonication, chilled water was circulated through the cooling jacket to maintain the solution temperature at $5 \pm 1{ }^{\circ} \mathrm{C}$.

\subsubsection{Homogenisation}

The homogeniser used was a GEA PandaPLUS 1000 (GEA Nitro Savi, Parma, Italy) equipped with a cell disruption valve. A single stage and single pass homogenisation was performed on $500 \mathrm{ml}$ of reconstituted WPC80 solution at an operating pressure of 80 bar. To ensure an equivalent energy density to sonication $(153 \mathrm{~J} / \mathrm{ml})$, the flow rate of the solution was set at $3.73 \mathrm{ml} / \mathrm{s}$. The power drawn was $570 \mathrm{~W}$. Calorimetric power was not calculated as the output energy is in the form of pressure rather than heat.

\subsubsection{Heat Treatment}

The following heat treatment methods are performed as described by Ashokkumar et al. (2009). For preheat treatments, $300 \mathrm{ml}$ of reconstituted WPC80 solution, at its natural $\mathrm{pH}$ of 6.29 , was pre-heated in a sealed, stainless steel tubular container fitted with a thermometer and an automated paddle stirrer of 2 by $1 \mathrm{~cm}$, rotating at $1000 \mathrm{~min}^{-1}$. The container was immersed in a water bath pre-heated to $80{ }^{\circ} \mathrm{C}$. The solution reached $80^{\circ} \mathrm{C}$ in $120 \pm 30 \mathrm{~s}$ and was then held at this temperature for $1 \mathrm{~min}$. After heating, the container was immediately removed from the water bath and placed in an ice bath for rapid cooling to approximately $20^{\circ} \mathrm{C}$.

For post-heating, $10 \mathrm{ml}$ of treated WPC80 solution was placed in a $27 \mathrm{ml}$ plastic container and sealed. The container was immersed in a water bath set at $85{ }^{\circ} \mathrm{C}$ for 20 mins. The temperature of the samples reached $70{ }^{\circ} \mathrm{C}$ in 10 mins and remained at temperatures greater than $70{ }^{\circ} \mathrm{C}$ for the remaining time. The container was removed from the water bath after heating and placed in an ice bath for rapid cooling to $20{ }^{\circ} \mathrm{C}$.

\section{3 Analysis}

\subsubsection{Acoustic Cavitation}

Acoustic cavitation is known to generate highly reactive hydroxyl radicals (Reaction 1), which in turn react to form hydrogen peroxide (Reaction 2). Iodide ions are oxidised by hydrogen peroxide to form molecular iodine (Reaction 3), which further reacts with free iodide ions to produce $\mathrm{I}_{3}{ }^{-}$(Reaction 4 ) 
(Alegria et al., 1989). Thus, the presence of an absorption band at $353 \mathrm{~nm}$, which corresponds to $\mathrm{I}_{3}{ }^{-}$, signifies acoustic cavitation.

$$
\begin{array}{rr}
\mathrm{H}_{2} \mathrm{O} \rightarrow \mathrm{H} \cdot+\mathrm{OH} \cdot & \text { Reaction 1 } \\
2 \mathrm{OH} \cdot \rightarrow \mathrm{H}_{2} \mathrm{O}_{2} & \text { Reaction 2 } \\
\mathrm{H}_{2} \mathrm{O}_{2}+2 \mathrm{I}^{-} \rightarrow \mathrm{I}_{2}+\mathbf{2 0 H ^ { - }} & \text { Reaction 3 } \\
\mathrm{I}_{2}+\mathrm{I}^{-} \rightarrow \mathrm{I}_{3}^{-} & \text {Reaction 4 }
\end{array}
$$

In the present work, hydrogen peroxide yield was measured using a method described by Alegria et al. (1989). Two solutions were prepared - Solution A consisted of $0.4 \mathrm{M}$ potassium iodide, $0.05 \mathrm{M}$ sodium hydroxide and $1.6 \times 10^{-4} \mathrm{M}$ ammonium molybdate while Solution B consisted of $0.1 \mathrm{M}$ potassium hydrogen phthalate. Deionised water was sonicated, mixed or homogenised, using the conditions given above, for 15 mins. $1 \mathrm{ml}$ of the freshly treated deionised water sample was then added to $1 \mathrm{ml}$ of Solution A and $1 \mathrm{ml}$ of Solution B. The solutions were left to stand for 5 mins prior to absorbance analysis at $353 \mathrm{~nm}$ using a Carey 50 Bio UV-visible spectrophotometer (Varian, Palo Alto, USA).

The presence of reactive radicals formed through cavitation can also be determined from the extent of degradation of phenol. During sonication, phenol reacts with hydroxyl radicals and degrades to dihydroxyphenols, catechol, hydroquinone, resorcinol and other intermediates (Mahamuni \& Pandit, 2006). A solution of $0.1 \mathrm{mM}$ phenol in deionised water was sonicated or homogenised using the conditions given above for $1 \mathrm{~h}$. High Performance Liquid Chromatography (HPLC, Shimadzu, Japan) was used to analyse the treated phenol solution for its degradation products. The solvent used was 60:40 methanol:water, the flow rate of the eluent was kept constant at $1 \mathrm{ml} / \mathrm{s}$ and the UV detection wavelength was $275 \mathrm{~nm}$.

\subsubsection{Particle Size Distribution}

The particle size distribution was determined using a Malvern Mastersizer 2000 laser diffraction system (Malvern Instruments, Malvern, UK). Refractive indices of 1.58 for whey protein agglomerates and 1.33 for the dispersant, which was water, with an absorption coefficient of 0.001 were used. Samples were shaken by hand before dispersion into water to obtain an obscuration (the amount of laser light lost upon passage through the sample) of $10 \%$. Mie theory (van de Hulst, 1957) was used to analyse the data, taken as the average of three measurements and expressed as the volume-weighted average particle size, D[4,3]. 


\subsubsection{Rheology}

To measure the viscosity of the solution, a $40 \mathrm{~mm}$ parallel plate geometry with a gap of $1 \mathrm{~mm}$ was used on an ARG2 Rheometer (TA Instruments, New Castle, USA). A conditioning step was first performed to equilibrate the sample to $25{ }^{\circ} \mathrm{C}$ followed by a continuous ramp step to obtain the viscosity profile at increasing shear rates from 10 to $200 \mathrm{~s}^{-1}$.

\section{Results and Discussion}

\subsection{Acoustic Cavitation}

Iodine tests as described above produced a peak at $353 \mathrm{~nm}$ for the sonicated sample but no peak in the high shear mixed or homogenised water samples (Figure 2). The absence of radical production suggests that cavitation - hydrodynamic or acoustic - does not result from either high shear mixing or homogenisation. However, to confirm that cavitation is absent in homogenisation, a second means of testing through phenol degradation was employed.

In this study, HPLC results showed that approximately $8 \%$ of phenol was degraded after $1 \mathrm{~h}$ of sonication. This is shown in Figure 3 where a reduction in the HPLC peak size corresponding to phenol at 17.2 min and the formation of two small peaks, due to intermediates formed during phenol degradation at 4.0 and 7.3 mins, are observed. Mahamuni et al. (2006) obtained similar results: $7 \%$ degradation of phenol was observed after 90 mins of sonication using a horn transducer. In both high shear mixing (data not shown) and homogenisation, the phenol peak remained unchanged and no product peaks were observed. Thus, it was confirmed that cavitation is absent under the homogenisation and high shear conditions employed.

\subsection{Sonication and Heat Stability}

A bimodal distribution of particles is seen in Figure 4a of native $5 \mathrm{wt} \%$ WPC80 solution. The relatively large peak between 10 to $100 \mu \mathrm{m}$ comprises large, insoluble, whey protein powder aggregates that are formed during the WPC manufacturing process (Zisu et al., 2011). Upon sonication, which generates high shear forces, this peak disappears as the large particles are reduced to less than $1 \mu \mathrm{m}$, giving an average D[4,3] of $0.19 \mu \mathrm{m}$ (Figure 5). Gülseren et al. (2007) observed an approximate $30 \%$ increase in particle size after sonication of bovine serum albumin (BSA), a component of whey proteins, for 30 mins. Through polyacrylamide gel electrophoresis (PAGE), no dimerisation was observed and hence determined that the aggregation of BSA was due to non-covalent interactions, such as electrostatic and hydrophobic interactions. However, their experiment used a protein that is only a minor constituent of whey and the sonication conditions were more severe with an ultrasonic intensity of $20 \mathrm{~W} / \mathrm{cm}^{2}$, double that used in this experiment $\left(10 \mathrm{~W} / \mathrm{cm}^{2}\right)$, and a much longer processing time. 
At low shear rates, the viscosity of the native sample decreased with increasing shear rates, indicating slight shear-thinning behaviour (Figure 6a). At higher shear rates, Newtonian behaviour is observed. Similar results were observed by Tang et al. (1993) for WPC solutions of less than $10 \mathrm{wt} \%$. The viscosity and flow behaviour of the sonicated solution is unchanged when compared to the native solution, as shown in Figure 6a. This may be due to the low viscosity of the native solution. Krešić et al. (2008) obtained an increase in viscosity in WPC and WPI solutions that were sonicated at 43 to $48 \mathrm{~W} / \mathrm{cm}^{2}$. They attributed this increase to the alteration of protein structure after sonication: hydrophilic portions of amino acids open towards the surrounding fluid, leading to a greater degree of binding to water molecules.

When pre-heat treatment was performed on the native solution, there was an increase in particle size of whey protein aggregates and the viscosity of the WPC80 solution (Figure $4 \mathrm{~b}$ and Figure $6 \mathrm{~b}$ ). This is due to heat-induced aggregation. At temperatures above the denaturation temperature and at its natural $\mathrm{pH}, \beta$ lactoglobulin ( $\beta-\mathrm{LG}$ ) dissociates into monomers, exposing the thiol groups that were previously buried in the macromolecule. These partially unfolded proteins then aggregate by thiol-disulphide exchange and interact further with each other by calcium bridging and hydrophobic bonding to form protein aggregates (Considine et al., 2007; Kato et al., 1983; Mleko, 2002; Sanchez et al., 1997). $\alpha$-lactalbumin ( $\alpha$-LA), a more stable protein, unfolds upon heating. However, as there is no free thiol group in $\alpha$-LA, it does not polymerise itself. When proteins that contain free thiol groups, such as $\beta$-LG, are present, $\alpha$-LA forms aggregates with these molecules by hydrophobic interactions or thiol-disulphide exchange (Considine $e t$ al., 2007; Oldfield et al., 2005; Oldfield et al., 2000). In a heated mixture of $\alpha$-LA and $\beta$-LG, studies have shown that large aggregates of $\beta$-LG are held together by disulphide bonds while aggregates with $\alpha$-LA are held together mainly by disulphide bonds and to a smaller extent, by hydrophobic interactions (Dalgleish et al., 1997; Havea et al., 1998; Matsudomi et al., 1993).

However, when the pre-heated sample was subsequently subjected to sonication, a sharp decrease in both particle size and viscosity was observed while maintaining the flow behaviour of the native sample (Figure $4 \mathrm{~b}$ and Figure $6 \mathrm{~b}$ ). The average particle size and viscosity of the PreH + US sample were $1.9 \mu \mathrm{m}$ and $3.0 \mathrm{cP}$, respectively (Figure 5). This may be due to the disruption of hydrophobic interactions by ultrasound-induced shear forces (Ashokkumar et al., 2009; Chandrapala et al., 2011).

As shown in Figure 4c and Figure 6c, for the control sample that has been pre-heated, a second heat treatment, in the form of post-heating, led to a further increase in particle size and viscosity, presumably due to further heat-induced aggregation. When a PreH + US WPC80 sample was subsequently re-heated, the low $\mathrm{D}[4,3]$, low viscosity and flow behaviour of the original sample are preserved, signifying the heat 
stability of the sample after sonication. Ashokkumar and co-workers (2009) found that these treated whey proteins are heat-stable even after freezing and spray-drying.

\subsection{Ultra-Turrax}

For the same energy density, with high shear mixing alone, there was a decrease in average aggregate size but not as significant as sonication (Figure 4a and Figure 5). In this case, the particle size reduction was due to the disruption of whey protein aggregates by mechanical shearing. The presence of a peak at D[4,3] greater than $3 \mu \mathrm{m}$ indicated that for the same energy density, high shear mixing was less energy efficient compared to sonication in reducing the size of whey protein aggregates. Although the flow behaviour of the mixed sample was unchanged, the viscosity was higher than that of the native and sonicated samples at low shear rates (Figure 6a). The formation of a thick foam was also observed within a minute of mixing (Figure 7). This was the result of the mechanism of the Ultra-Turrax unit, which draws air into the unit together with the bulk solution. The expulsion of this mixture of solution and air produces foam, which reduces energy efficiency. This foam was unstable, breaking down when left undisturbed. It is likely that it is this foam formation that leads to the observed increase in viscosity.

For a pre-heated and mixed sample, in Figure $4 \mathrm{~b}$, a unimodal distribution at $\mathrm{D}[4,3]$ of 2 to $20 \mu \mathrm{m}$ was obtained. Whey protein aggregates were less reduced in size as compared to the pre-heated and sonicated sample (Figure 5). This confirms the low energy efficiency of high shear mixing. Similar to the particle size results, the viscosity decreased when high shear mixing was performed on the heated sample (Figure $6 b)$. Foaming of the solution was once again observed. Upon post-heating, the average particle size of the whey protein aggregates and the viscosity of the solution were maintained (Figure $4 \mathrm{c}$ and Figure 6c). Hence, heat stability was also achieved with high shear mixing.

\subsection{Homogenisation}

Upon homogenisation of the native $5 \mathrm{wt} \%$ WPC80 sample, the particle size distribution obtained was similar to that of a sonicated sample, giving an identical D[4,3] value (Figure 4a). Both Bouaouin et al. (2006) and Sanchez et al. (1997) reported a particle size reduction when homogenisation was performed on whey protein isolate (WPI) solutions. The disruption of protein aggregates is the result of a pressure gradient, which induces cavitation, shear and turbulence simultaneously, and in turn disrupts intramolecular hydrophobic and electrostatic interactions (Bouaouina et al., 2006; Paquin, 1999). The shear-thinning behaviour of the sample was preserved after homogenisation, however, the viscosity was slightly higher at low shear rates as compared to the native sample. Grácia-Juliá et al. (2008) observed no change in viscosity when $10 \mathrm{wt} \%$ WPI solution was treated using homogenising pressures of up to $225 \mathrm{MPa}$. Above that, there was an increase in viscosity upon homogenisation. Similarly, 
Krešić et al. (2008) reported an increase in viscosity with no change in flow behaviour in both 10 wt\% WPC and WPI solutions upon high pressure treatment at $500 \mathrm{MPa}$. The viscosity increase was attributed to the presence of high molecular weight aggregates and the increase in the volume occupied by the unfolded protein due to the loss of the tertiary structure (Krešić et al., 2008).

As shown in Figure 4b and Figure 6b, the particle size distribution and viscosity of a pre-heated and homogenised sample was again similar to that of a pre-heated and sonicated sample. The $\mathrm{D}[4,3]$ obtained for the pre-heated and homogenised and pre-heated and sonicated samples were 1.6 and $1.5 \mu \mathrm{m}$ respectively while the viscosities obtained at a shear rate of $200 \mathrm{~s}^{-1}$ were 3.1 and $2.9 \mathrm{cP}$ respectively. This shows that for the same energy density, both sonication and homogenisation gave similar particle size and viscosity effects. Thus, the forces generated during homogenisation are as effective as those generated by sonication for equal energy for both systems. Upon post-heating, the average particle size and viscosity are maintained (Figure 4c, Figure 5 and Figure 6c). Thus, heat stability is also achieved with homogenisation and is not unique to sonication alone. This suggests that shear forces alone are sufficient to cause these effects since cavitation was not observed for homogenisation.

At higher homogenising pressures, the average particle size was similar for all non-heated, homogenised samples (Figure 8). This suggests that a pressure of 80 bar is sufficient for complete disruption of all noncovalent forces in the native whey protein aggregates. Both Bouaouina et al. (2006) and Paquin (1999) indicate that homogenisation will only disrupt non-covalent forces. Bouaouina et al. (2006) observed a narrower particle size distribution, with a large proportion of the particles found to be less than $1 \mu \mathrm{m}$, at increasing homogenising pressures of WPI solutions due to greater disruption of aggregates. On the other hand, Dissanayake and Vasiljevic (2009) microfluidised whey protein retentate and observed a wider particle size distribution in non-heat treated samples with increasing pressure. This may have been due to protein denaturation induced by high pressure which changes the equilibrium between the interactions that stabilise the conformation of native proteins (Considine et al., 2007; Dissanayake \& Vasiljevic, 2009). As shown in Figure 8, for samples that have undergone heat treatment, the average particle size decreased gradually with increasing pressure. Unlike non-heated samples, there are more protein-protein interactions to be broken in pre-heated samples. Thus, when there is an increase in pressure, a greater proportion of these forces are disrupted

\section{Conclusion}

Various treatments - sonication, high shear mixing and homogenisation - were performed on $5 \mathrm{wt} \%$ WPC80 solution with a combination of heat treatment. At identical energy density, smaller reductions in particle size and viscosity were observed in the high shear mixed samples, suggesting a lower energy 
efficiency. Both sonication and homogenisation provided similar particle sizes and viscosity reductions. This suggests that whey protein aggregates can be disrupted to the same extent by both approaches. In addition, heat stability was achieved in all systems, showing that this effect is the result of shear forces, which is either generated directly in high shear mixing and homogenisation devices or induced by acoustic cavitation in a sonicator. Therefore, the combination of a heat treatment followed by any suitable high shear process is capable of producing a low viscosity, heat stable product.

\section{Acknowledgements}

This work was supported by Dairy Innovation Australia, the Particulate Fluids Processing Centre, A Special Research Center of the Australian Research Council and by the Australian Research Council Linkage Project (LP LP0991048).

\section{References}

Alegria AE, Lion Y, Kondo T \& Riesz P (1989) Sonolysis of aqueous surfactant solutions: probing the interfacial region of cavitation bubbles by spin trapping. The Journal of Physical Chemistry, 93(12), 4908-4913.

Ashokkumar M, Lee J, Zisu B, Bhaskarcharya R, Palmer M \& Kentish S (2009) Sonication increases the heat stability of whey proteins. Journal of Dairy Science, 92(11), 5353-5356.

Bouaouina H, Desrumaux A, Loisel C \& Legrand J (2006) Functional properties of whey proteins as affected by dynamic highpressure treatment. International Dairy Journal, 16(4), 275-284.

Chandrapala J, Zisu B, Palmer M, Kentish S \& Ashokkumar M (2011) Effects of ultrasound on the thermal and structural characteristics of proteins in reconstituted whey protein concentrate. Ultrasonics Sonochemistry, 18(5), 951-957.

Considine T, Patel HA, Anema SG, Singh H \& Creamer LK (2007) Interactions of milk proteins during heat and high hydrostatic pressure treatments - A Review. Innovative Food Science and Emerging Technologies, 8(1), 1-23.

Dalgleish DG, Senaratne V \& Francois S (1997) Interactions between $\alpha$-Lactalbumin and $\beta$-Lactoglobulin in the Early Stages of Heat Denaturation. Journal of Agricultural and Food Chemistry, 45(9), 3459-3464.

Deysher EF, Webb BH \& Holm GE (1929) The relations of temperature and time of forewarming of milk to the heat stability of its evaporated product. Journal of Dairy Science, 7(1), 80-89.

Dissanayake M \& Vasiljevic T (2009) Functional properties of whey proteins affected by heat treatment and hydrodynamic highpressure shearing. Journal of Dairy Science, 92(4), 1387-1397.

Floury J, Bellettre J, Legrand J \& Desrumaux A (2004) Analysis of a new type of high pressure homogeniser. A study of the flow pattern. Chemical Engineering Science, 59(4), 843-853.

Grácia-Juliá A, René M, Cortés-Muñoz M, Picart L, López-Pedemonte T, Chevalier D \& Dumay E (2008) Effect of dynamic high pressure on whey protein aggregation: A comparison with the effect of continuous short-time thermal treatments. Food Hydrocolloids, 22(6), 1014-1032.

Gülseren İ, Güzey D, Bruce BD \& Weiss J (2007) Structural and functional changes in ultrasonicated bovine serum albumin solutions. Ultrasonics Sonochemistry, 14(2), 173-183.

Havea P, Singh H, Creamer LK \& Campanella OH (1998) Electrophoretic characterization of the protein products formed during heat treatment of whey protein concentrate solutions. Journal of Dairy Research, 65(01), 79-91.

Ika. (2009). Ika Ultra-Turrax T25 Digital Instruction Manual. IKA Works GmbH \& Co. 
Iordache M \& Jelen P (2003) High pressure microfluidization treatment of heat denatured whey proteins for improved functionality. Innovative Food Science and Emerging Technologies, 4(4), 367-376.

Kato A, Osako Y, Matsudomi N \& Kobayashi K (1983) Changes in the emulsifying and foaming properties of proteins during heat denaturation. Agricultural Biological Chemistry, 47(1), 33-37.

Krešić G, Lelas V, Jambrak AR, Herceg Z \& Brnčić SR (2008) Influence of novel food processing technologies on the rheological and thermophysical properties of whey proteins. Journal of Food Engineering, 87(1), 64-73.

Mahamuni NN \& Pandit AB (2006) Effect of additives on ultrasonic degradation of phenol. Ultrasonics Sonochemistry, 13(2), $165-174$.

Matsudomi N, Oshita T, Kobayashi K \& Kinsella JE (1993) $\alpha$-Lactalbumin enhances the gelation properties of bovine serum albumin. Journal of Agricultural and Food Chemistry, 41(7), 1053-1057.

Mleko S (2002) Gelation of shear treated whey protein polymers/aggregates. Journal of Food Science and Technology, 39(2), 167-169.

Morr CV \& Richter RL (1999) Chemistry of Processing. In: Wong NP, Jenness R, Keeney M \& Marth EH (eds.) Fundamentals of Dairy Chemistry, pp 739-766. Aspen Publishers, New York.

Oldfield DJ, Singh H \& Taylor MW (2005) Kinetics of heat-induced whey protein denaturation and aggregation in skim milks with adjusted whey protein concentration. Journal of Dairy Research, 72(03), 369-378.

Oldfield DJ, Singh H, Taylor MW \& Pearce KN (2000) Heat-induced interactions of $\beta$-lactoglobulin and $\alpha$-lactalbumin with the casein micelle in pH-adjusted skim milk. International Dairy Journal, 10(8), 509-518.

Oldrup J. (2006). Application: WO Patent No. 2005-DK760.

Onwulata CI, Konstance RP \& Tomasula PM (2002) Viscous properties of microparticulated dairy proteins and sucrose. Journal of Dairy Science, 85(7), 1677-1683.

Paquin P (1999) Technological properties of high pressure homogenizers: the effect of fat globules, milk proteins, and polysaccharides. International Dairy Journal, 9(3-6), 329-335.

Sanchez C, Pouliot M, Gauthier SF \& Paquin P (1997) Thermal aggregation of whey protein isolate containing microparticulated or hydrolyzed whey proteins. Journal of Agricultural and Food Chemistry, 45(7), 2384-2392.

Singh H (2004) Heat stability of milk. International Journal of Dairy Technology, 57(2/3), 111-119.

Tang Q, Munro PA \& McCarthy OJ (1993) Rheology of whey protein concentrate solutions as a function of concentration, temperature, $\mathrm{pH}$ and salt concentration. Journal of Dairy Research, 60(3), 349-361.

Tolkach A \& Kulozik U (2007) Reaction kinetic pathway of reversible and irreversible thermal denaturation of $\beta$-lactoglobulin. Lait, 87(4-5), 301-315.

van de Hulst HC (1957) Light Scattering by Small Particles. John Wiley and Sons, New York.

Wang Q, Tolkach A \& Kulozik U (2006) Quantitative assessment of thermal denaturation of bovine $\alpha$-lactalbumin via lowintensity ultrasound, HPLC, and DSC. Journal of Agricultural and Food Chemistry, 54(18), 6501-6506.

Webb BH \& Bell RW (1942) The effect of high-temperature short-time forewarming of milk upon the heat stability of its evaporated product. Journal of Dairy Science, 25(4), 301-311.

Zisu B, Bhaskaracharya R, Kentish S \& Ashokkumar M (2010) Ultrasonic processing of dairy systems in large scale reactors. Ultrasonics Sonochemistry, 17(6), 1075-1081.

Zisu B, Lee J, Chandrapala J, Bhaskaracharya R, Palmer M, Kentish S \& Ashokkumar M (2011) Effect of ultrasound on the physical and functional properties of reconstituted whey protein powders. Journal of Dairy Research, 78(2), $226-232$. 


\section{List of Figures}

Figure 1: Flow chart of various treatment of samples, where PreH denotes pre-heat treatment, $\mathrm{T}$ symbolises treatment method, sonication (US), Ultra-Turrax (UT) or homogenisation (HR), and PostH represents post-heat treatment. The number in the brackets indicates sample number.

Figure 2: Absorbance spectra of control and treated samples, where a band centred at $353 \mathrm{~nm}$ represents the absorbance of $\mathrm{I}_{3}{ }^{-}$. The control sample was distilled water and the treatments used were sonication, high shear mixing by an Ultra-Turrax unit and homogenisation.

Figure 3: HPLC data of $1 \mathrm{mM}$ phenol samples, where a peak at 17.3 min corresponds to phenol and two peaks at 4.0 and 8.3 mins represent intermediates. The treatments used were sonication and homogenisation.

Figure 4: Particle size distribution of reconstituted 5 wt\% WPC80 solutions: (a) Samples 1 to 4, (b) Samples 5 to 8 and (c) Samples 9 to 12 .

Figure 5: Summary of dynamic viscosity at a shear rate of $200 \mathrm{~s}^{-1}(\mathrm{cP})$ and volume-weighted average particle size, $\mathrm{D}[4,3],(\mu \mathrm{m})$ for all samples.

Figure 6: Change in apparent viscosity $(\mathrm{cP})$ with respect to increasing shear rate $\left(\mathrm{s}^{-1}\right)$ of (a) Samples 1 to 4, (b) Samples 5 to 8 and (c) Samples 9 to 12. All solutions exhibit shear-thinning behaviour.

Figure 7: Before (a) and after (b) pictures of high shear mixing of $5 \mathrm{wt} \%$ WPC80 solution at $17500 \mathrm{~min}^{-1}$ for 2 mins $11 \mathrm{~s}$. A substantial volume of foam was formed after mixing.

Figure 8: Volume-weighted average particle size, D[4,3] $(\mu \mathrm{m})$, at homogenisation pressures of 80, 160 and 250 bar for homogenised (HR), pre-heated and homogenised (PreH + HR) and pre-heated, homogenised and post-heated $(\mathrm{PreH}+\mathrm{HR}+\mathrm{PostH})$ samples. 


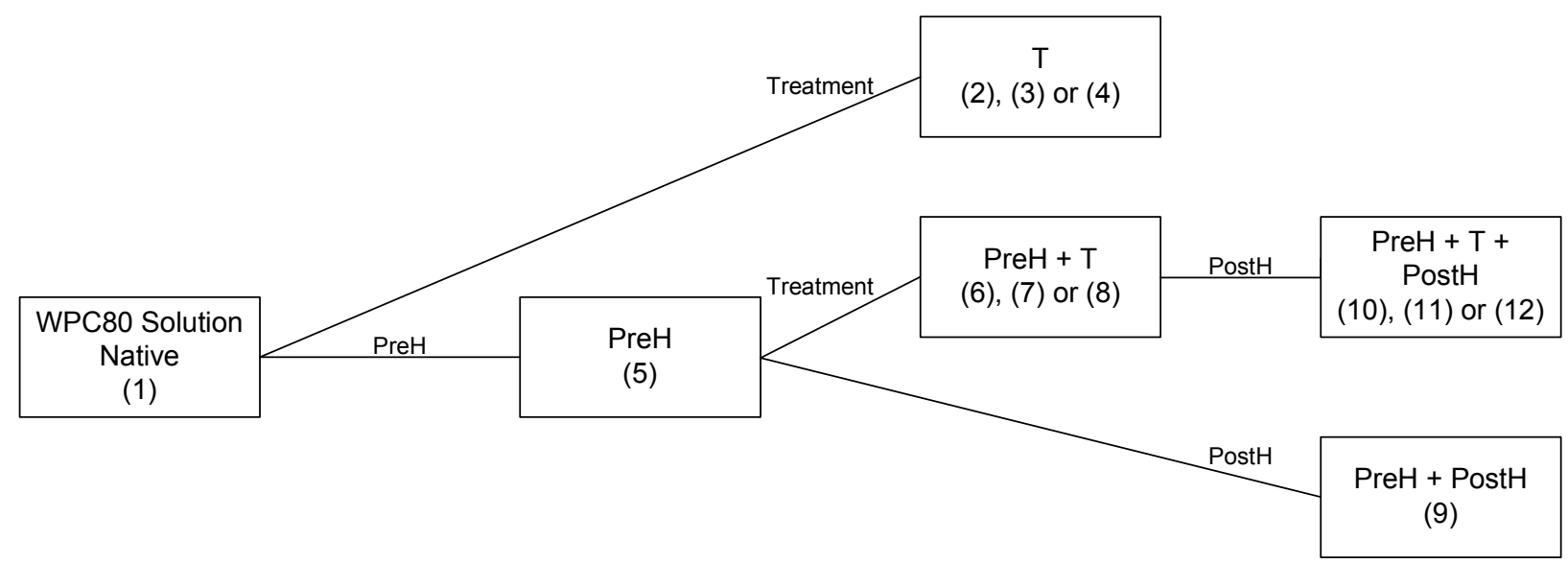

Figure 1 


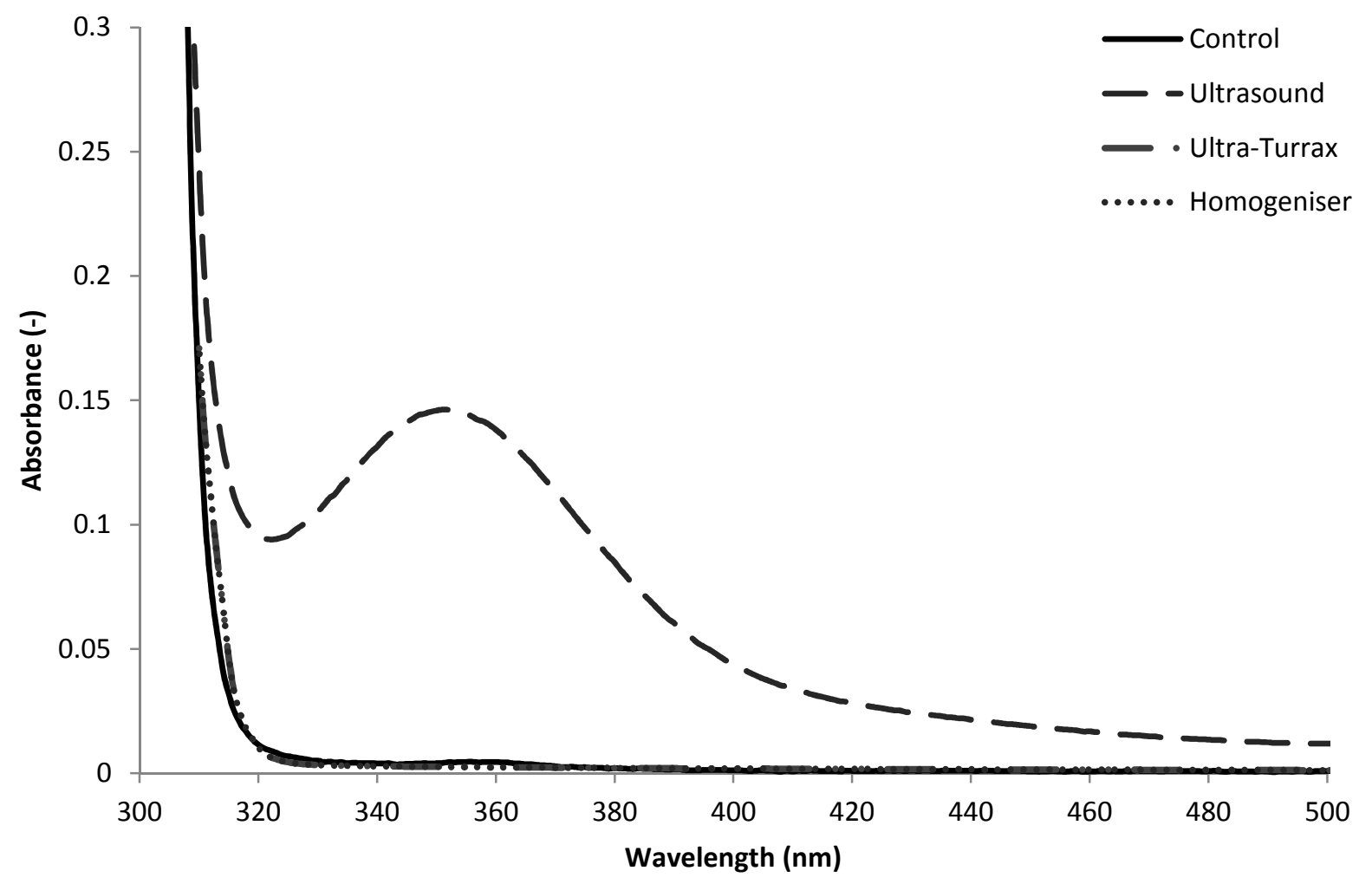

Figure 2 


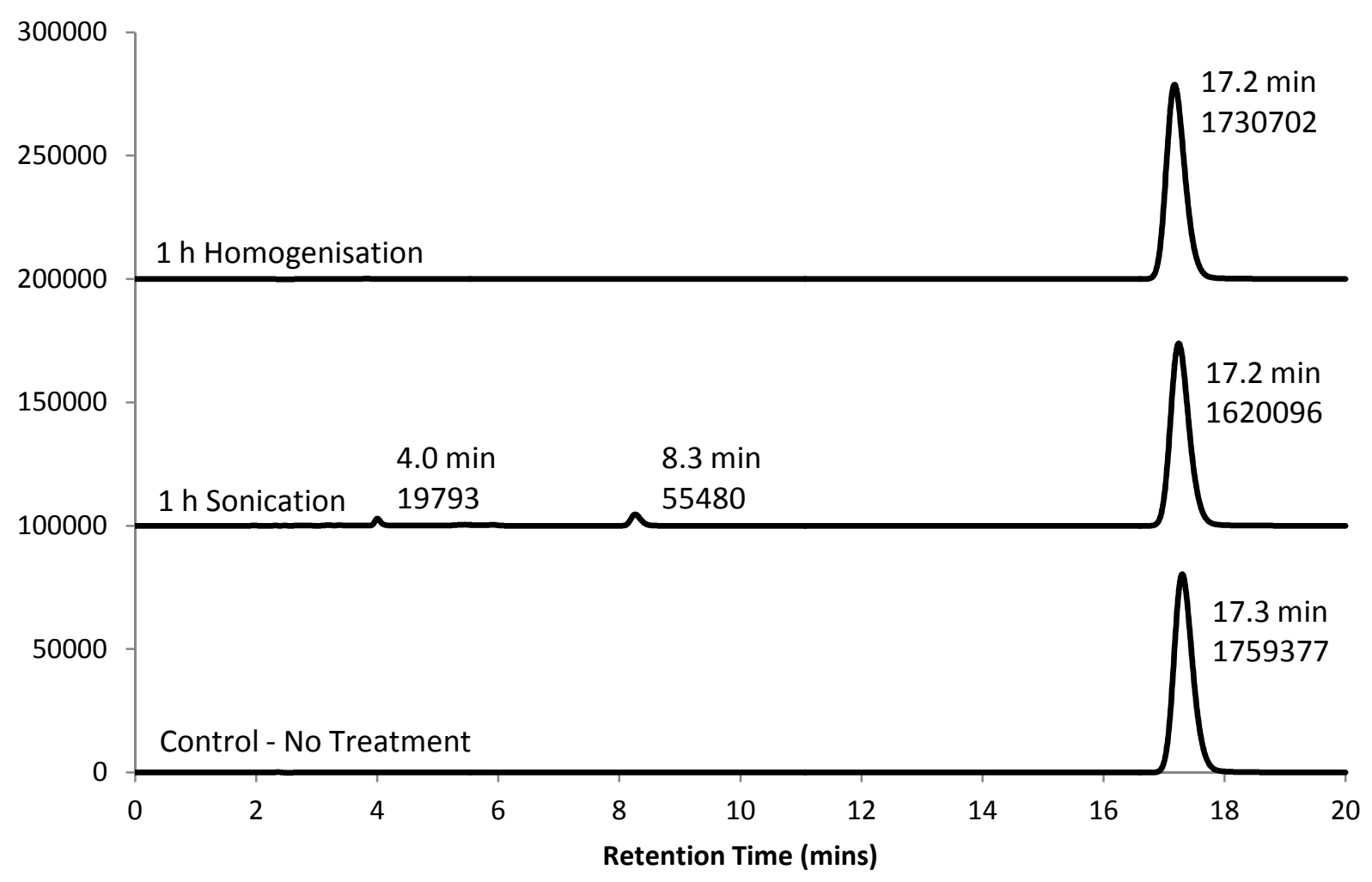

Figure 3 

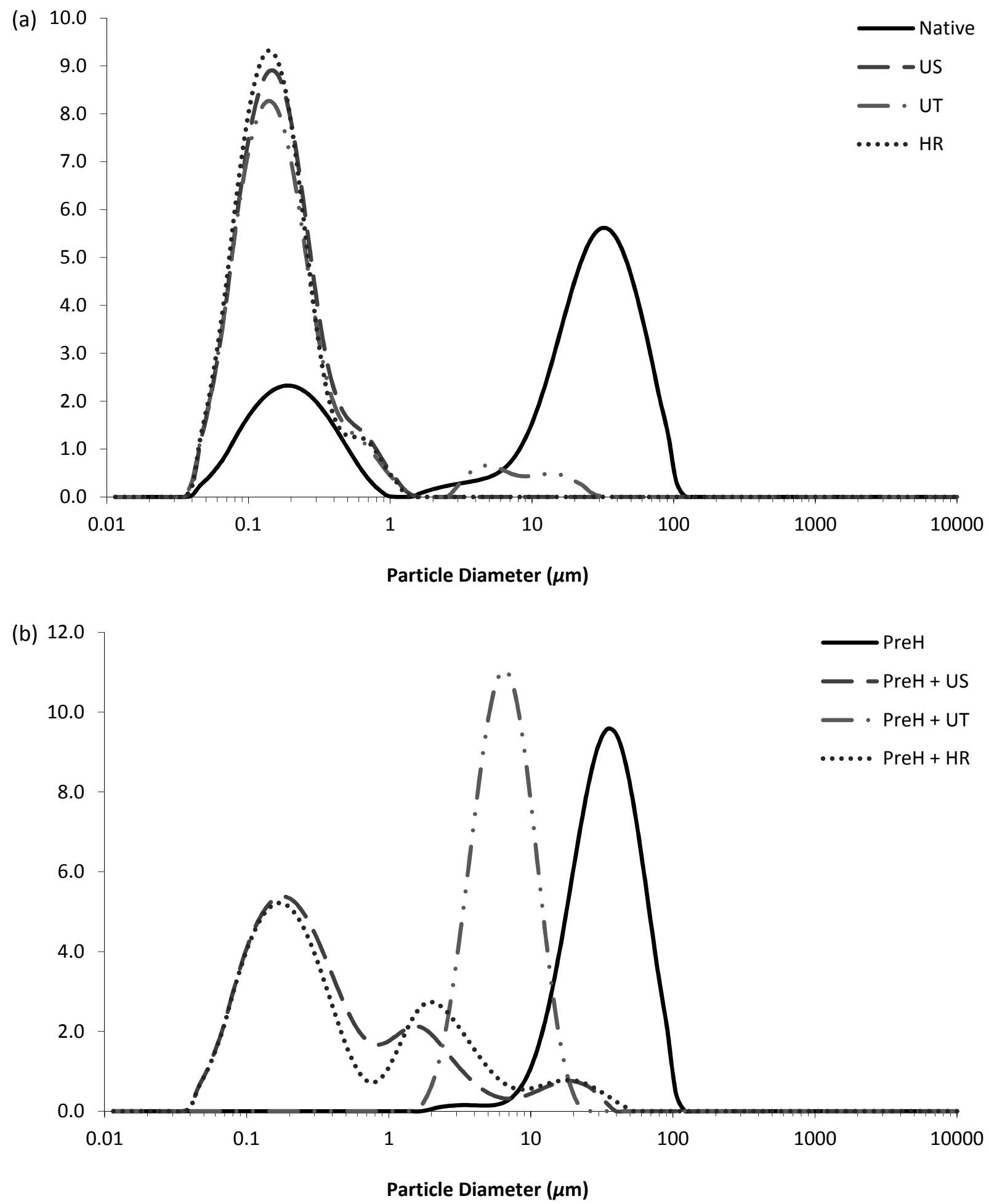


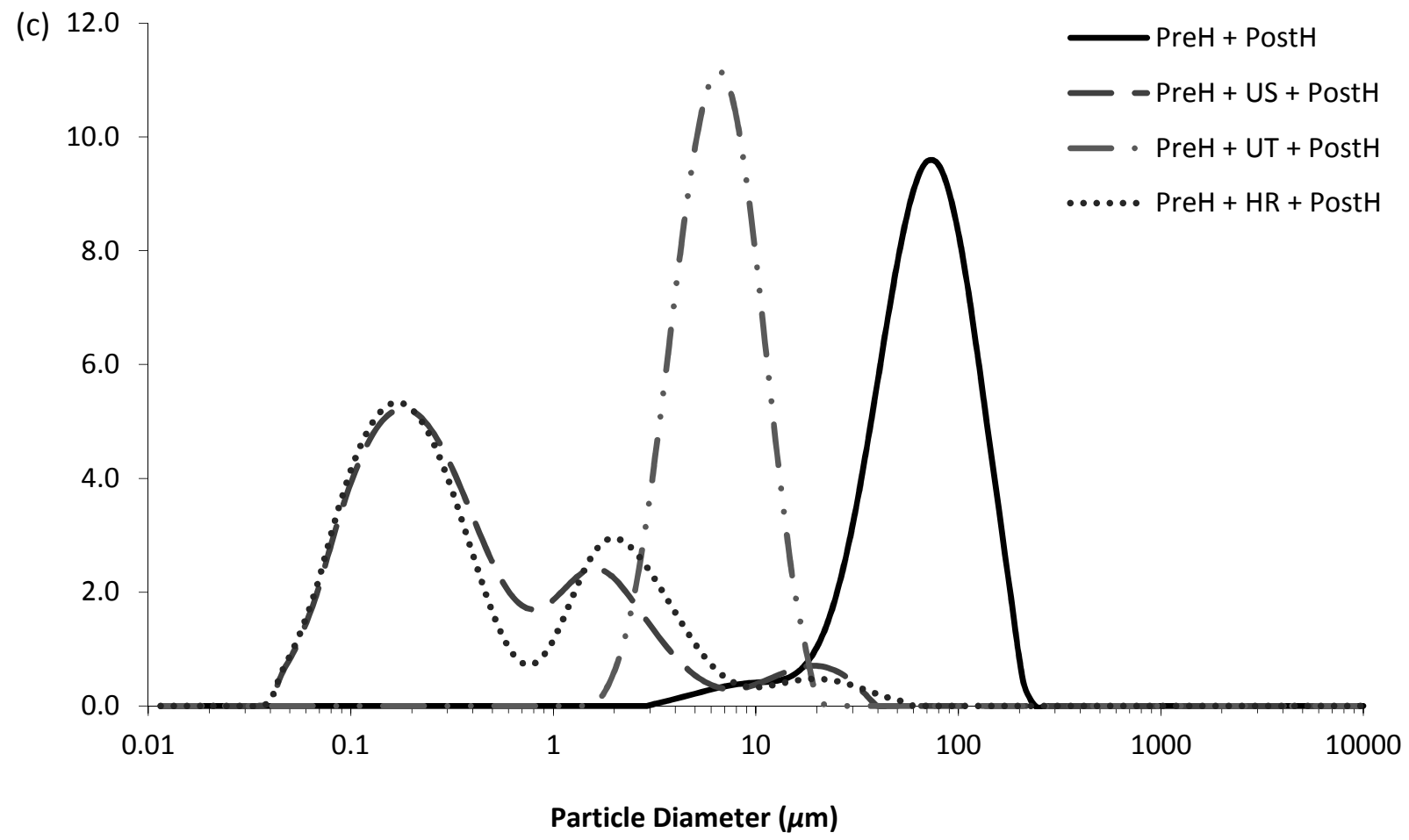

Figure 4 


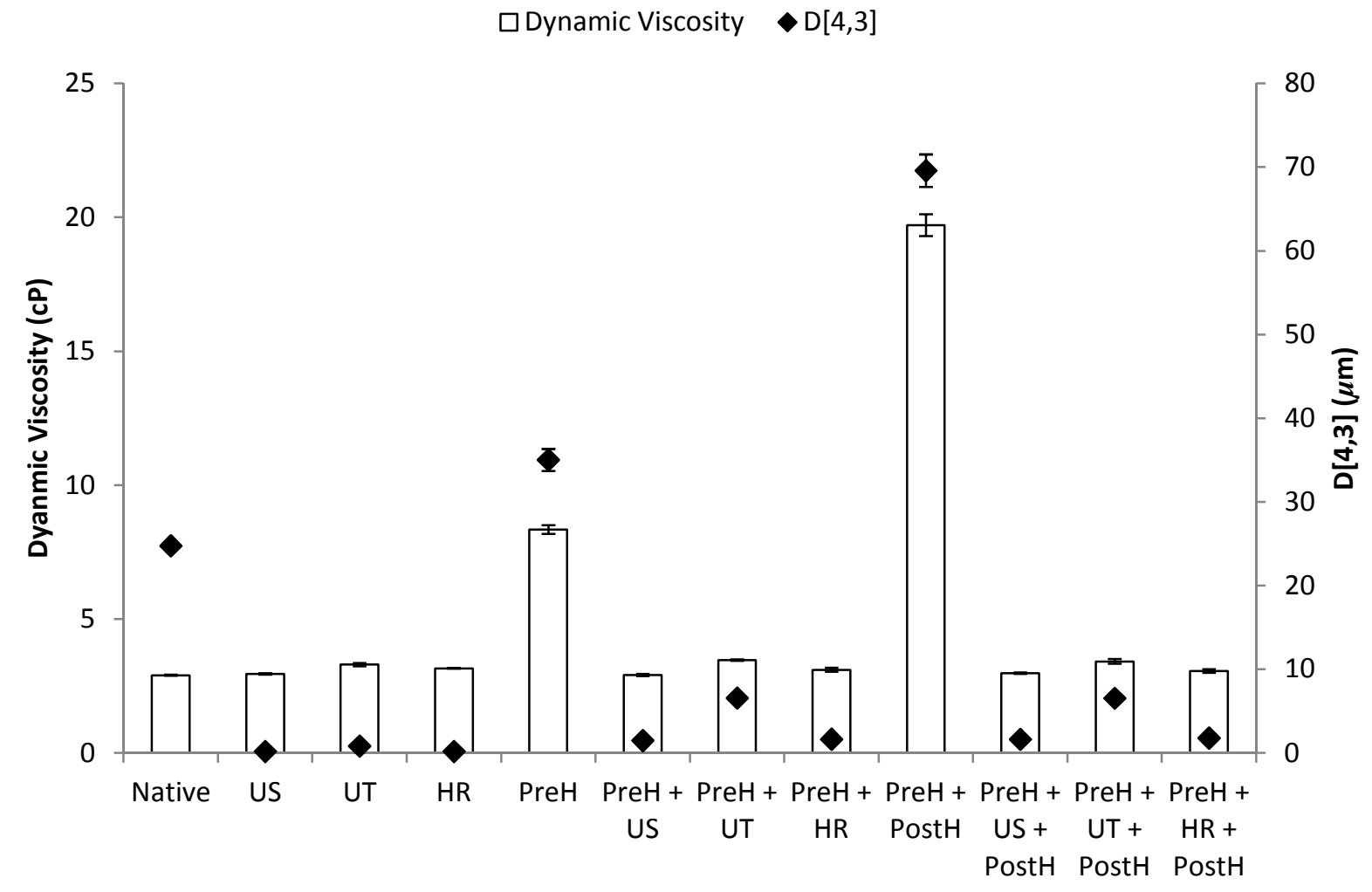

Figure 5 

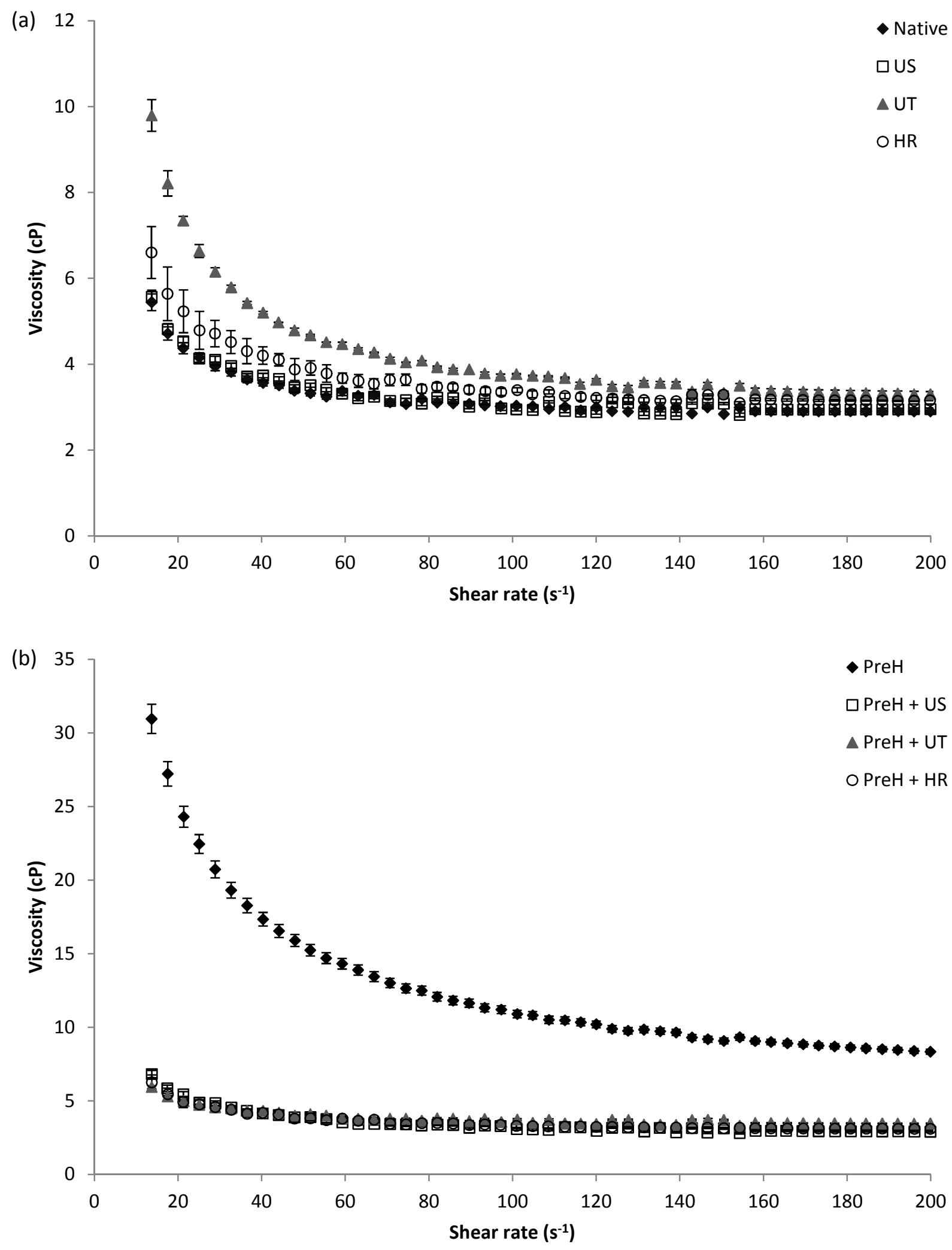


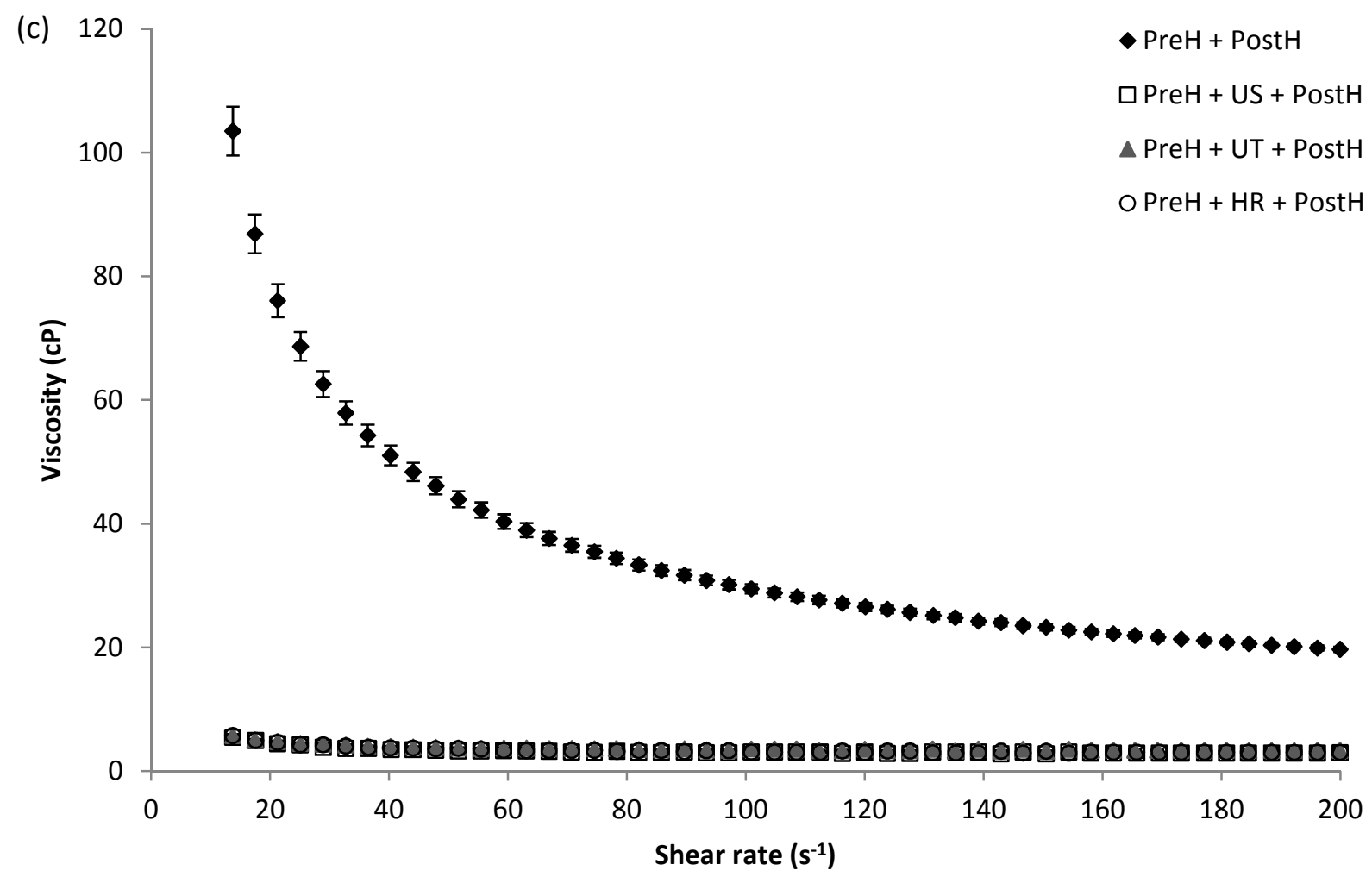

Figure 6 

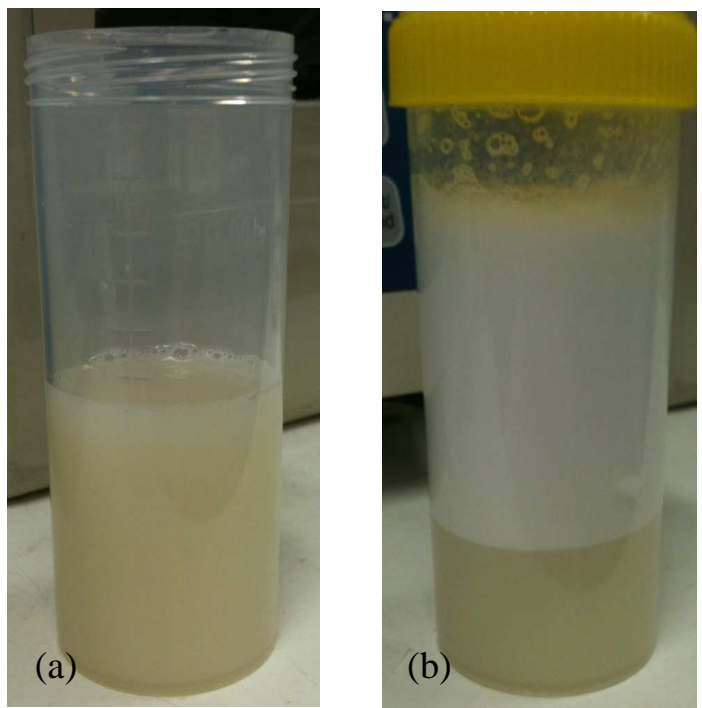

Figure 7 


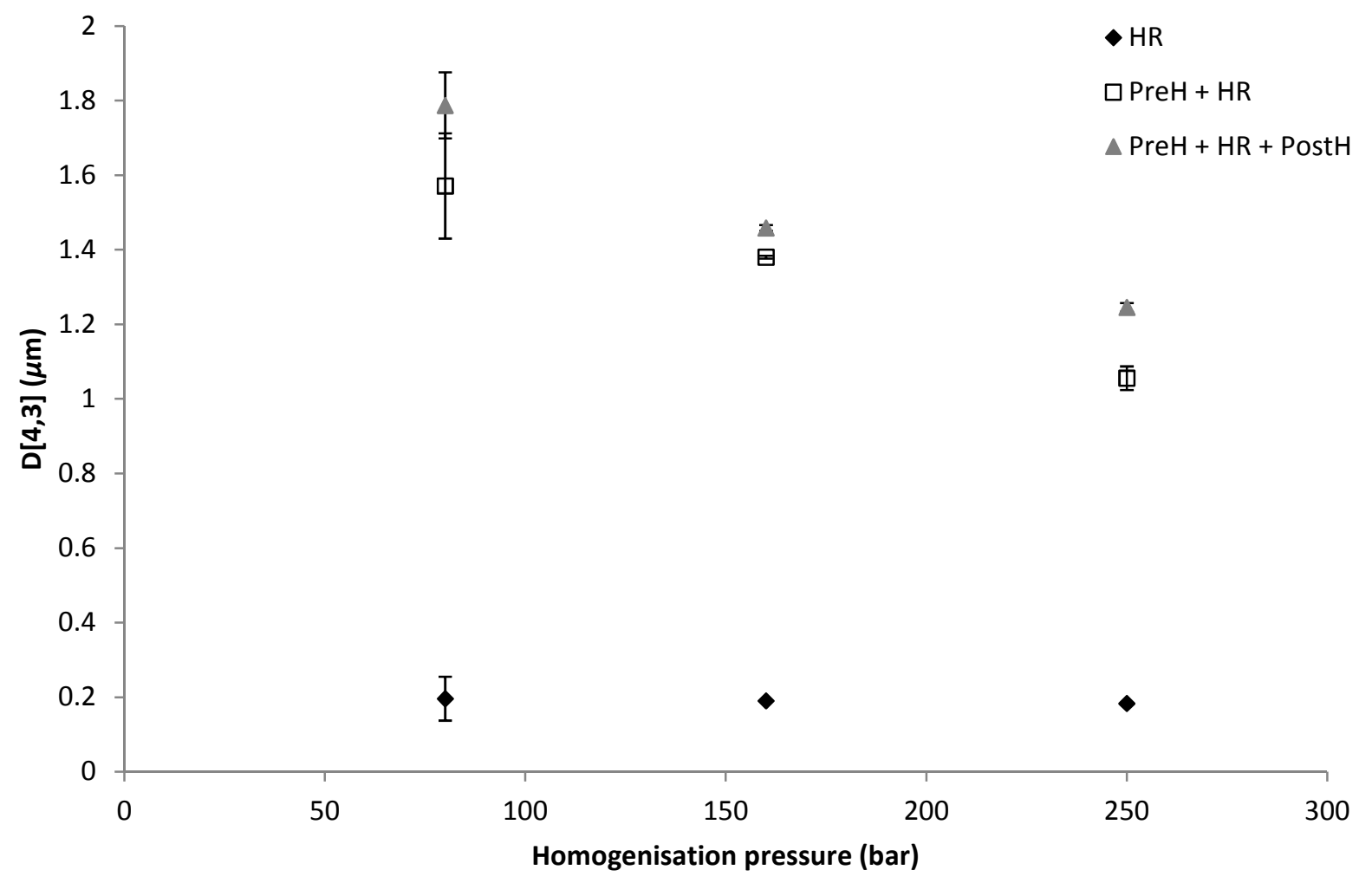

Figure 8 


\section{University Library}

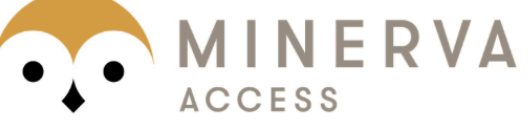

A gateway to Melbourne's research publications

Minerva Access is the Institutional Repository of The University of Melbourne

Author/s:

Koh, LLA;Chandrapala, J;Zisu, B;Martin, GJO;Kentish, SE;Ashokkumar, M

Title:

A Comparison of the Effectiveness of Sonication, High Shear Mixing and Homogenisation on Improving the Heat Stability of Whey Protein Solutions

Date:

2014-02-01

\section{Citation:}

Koh, L. L. A., Chandrapala, J., Zisu, B., Martin, G. J. O., Kentish, S. E. \& Ashokkumar, M. (2014). A Comparison of the Effectiveness of Sonication, High Shear Mixing and Homogenisation on Improving the Heat Stability of Whey Protein Solutions. FOOD AND BIOPROCESS TECHNOLOGY, 7 (2), pp.556-566. https://doi.org/10.1007/ S11947-013-1072-1.

Persistent Link:

http://hdl.handle.net/11343/283319 